D.O.I.: $10.3895 / \mathrm{S} 1808-04482007000300011$

\title{
O DESIGN NA PESQUISA QUALI-QUANTITATIVA EM ENGENHARIA DE PRODUÇÃO - QUESTÕES A CONSIDERAR
}

\section{THE DESIGN IN THE QUALI-QUANTITATIVE RESEARCH IN THE PRODUCTION ENGINEERING - QUESTIONS TO BE CONSIDERED}

\begin{abstract}
Leonardo Ensslin ${ }^{1}$; Sandra Rolim Ensslin ${ }^{2}$; William Barbosa Vianna ${ }^{3}$
${ }^{1}$ Universidade Federal de Santa Catarina (UFSC) - Programa de Pós Graduação em Engenharia de Produção (PPGEP)- LabMCDA (Laboratório de Multicritério em Apoio à Decisão) - Florianópolis - SC - Brasil - leonardoensslin@terra.com.br

${ }^{2}$ Universidade federal de Santa Catarina (UFSC) - Programa de Pós Graduação em Engenharia de Produção (PPGEP) - LabMCDA (Laboratório de Multicritério em Apoio à Decisão) - Florianópolis - SC - Brasil - ensslin@deps.ufsc.br

${ }^{3}$ Universidade federal de Santa Catarina (UFSC) - Programa de Pós Graduação em Engenharia de Produção (PPGEP) - LabMCDA (Laboratório de Multicritério em Apoio à Decisão) - Florianópolis - SC - Brasil - wpwilliam@hotmail.com
\end{abstract}

\begin{abstract}
Resumo
O presente artigo de natureza teórica pretende apresentar uma proposta de design de pesquisa operacional aplicado à engenharia de produção que contemple os elementos materiais e formais do processo investigativo, concentrando a discussão nas bases epistemológicas do desenvolvimento cientifico, nos critérios internos e externos de validade da pesquisa operacional soft e na formação do pesquisador como elemento primário e estratégico do processo de produção de conhecimento critico e valido nessa área do conhecimento. $O$ artigo divide-se em quatro secções sendo que inicialmente apresenta-se a controvérsia entre Popper e Kuhn quanto à cientificidade e método cientifico para em seguida apresentar o constructo dos autores a esse respeito. Em seguida caracterizam-se os métodos qualitativos e quantitativos e justifica-se a necessidade de predominância da abordagem quali-quantitativa em algumas áreas da engenharia de produção. A terceira secção trata do projeto de pesquisa ou design de pesquisa, suas características, seus elementos materiais e formais, o uso disciplinado de critérios de validação interna e externa e o seu uso na formação do pesquisador.
\end{abstract}

Palavras-chave: Pesquisa operacional soft, pesquisa quali-quantitativa em engenharia de produção, multicritério.

\section{Introdução}

No ambiente da Pesquisa Operacional Soft aplicada à Engenharia de Produção em geral e particularmente tratando-se do Apoio à Decisão, define-se como problema que a falta de clareza e a 
dicotomia entre a natureza metodológica do Design e a pergunta de pesquisa conduz a resultados equivocados e inválidos sob a forma de soluções "ótimas" baseadas em modelos matemáticos e simulações ausentes de clareza quanto ao problema, sua natureza, os objetivos da pesquisa, a seleção de critérios sob os quais o problema será abordado e a própria cientificidade.

O evidenciamento de um Design de pesquisa como mapa de navegação e roteiro metodológico é capaz de reduzir essas dicotomias e a predominância do método quali-quantitativo apresenta-se como o mais adequado em vista da natureza dos problemas na Pesquisa Operacional Soft, admitindo-se o construtivismo como visão de conhecimento. Segundo Landry (1991), a definição de problema é de importância central no processo de encontrar as formas para solucionálo, na literatura isto é amplamente reconhecido, mas na prática é ignorado. O desenvolvimento do Design de pesquisa faz parte, dessa forma, de uma proposta de operacionalização metodologica na Pesquisa Cientifica, enquadrando-se nas etapas propostas por Petri (2005).

Figura 1: Modelo para escolha da Metodologia de Pesquisa Científica

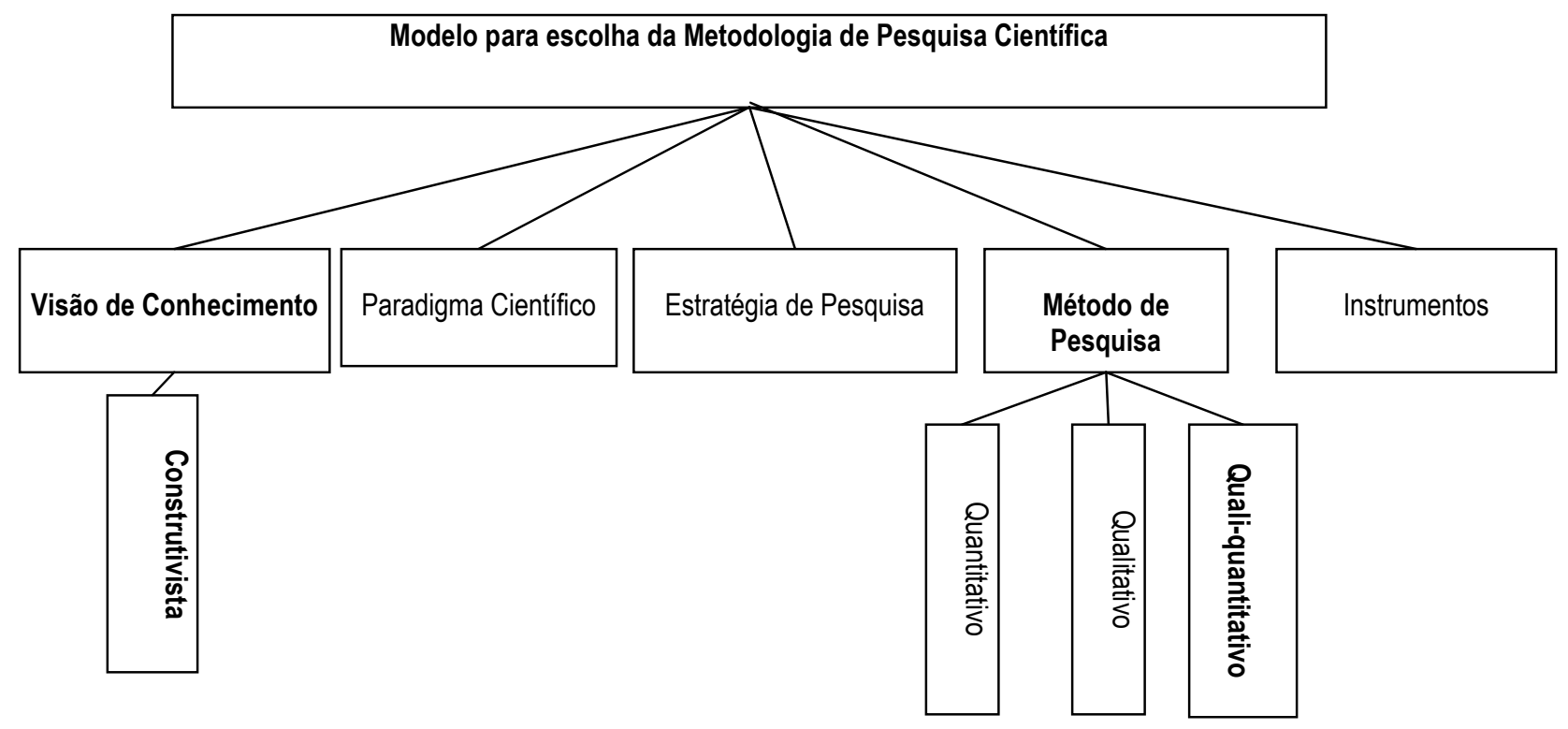

Fonte: Adaptado de Petri (2005)

\section{Cientificidade e crítica do conhecimento em Popper e Kuhn}

Acentuadamente a partir da década de 60, as vertentes noções de linearidade do conhecimento vêm demonstrando-se cada vez mais insuficiente como base de constituição de saberes científicos, sobretudo aqueles cujos pressupostos de método destacam-se por características segundo as quais o conhecimento deve ser obtido a partir da observação de caráter indutivo e somente a experiência empírica pode ser a fonte do conhecimento e nesses domínios é que as sentenças têm valor científico. 
Tomando como base a crise da física no inicio do século XX, a partir da exploração das questões atômicas, temos um confronto radical com os antigos modelos positivistas e empiristas de ciência nos quais os modos do pensar mostraram-se inadequados para descrever determinados fenômenos, situando na mesma arena de discussão, físicos e filósofos, de onde tomaremos duas importantes posições.

A partir de críticas à indução, o filósofo Karl Popper (1902-1994) construiu o que é convencionalmente chamado de racionalismo crítico particularmente em a "Lógica da Investigação Científica” (Popper, 1998). Não concebendo a possibilidade de que o futuro vá repetir o passado, conclui que o critério da indução não é racionalmente aceitável.

Nessa perspectiva, o conhecimento em geral e o método cientifico em particular, progridem através de teorias, hipóteses, conjeturas e refutações, contando com o apoio da lógica dedutiva na comparação entre diversas teorias que são discutidas criticamente com vistas a detectar sua validade e aplicabilidade a determinado problema em questão, num constante processo de validação e novidade.

Nessa perspectiva ainda, Popper (1998) considera o progresso cientifico numa dimensão hipotético-dedutiva, não como acumulação de observações, mas na repetida superação de teorias cientificas por outras melhores e mais satisfatórias e aí estaria o caráter permanentemente revolucionário das ciências que progrediriam a partir de um método de ensaio e erro.

Apesar dessa lógica de Popper (falseabilidade) ser diferente da dos positivistas lógicos e empiristas (verificacionismo), a conclusão em relação às afirmações continua a mesma, apenas de forma inversa ao inducionismo, tornando precários alguns de seus postulados teóricos.

Porém, sua relevância está na introdução de criticidade ao processo de produção cientifica e à sua metodologia até então positivista e empírica, inquestionável, bem como aprofundar o entendimento de que não existe teoria totalmente verdadeira; nenhuma teoria consegue compreender, abarcar ou verificar todas as situações possíveis, ou seja, a objetividade absoluta é uma miragem.

No mesmo contexto de critica investigativa da cientificidade e do método cientifico surge uma outra posição muito relevante e mais avançada a partir do estudo de Thomas Kuhn (19221996), físico, em “A Estrutura das Revoluções Científicas” (1962). O texto traz à tona o uso do conceito de "paradigma", que na filosofia significa modelo ou exemplo. Os estudos desse autor foram predominantemente realizados com base na análise do progresso científico ocorrido na Física no contexto da História da Ciência. Apoiado em sua visão da história da ciência, Kuhn critica tanto Popper quanto os indutivistas, alegando que sempre é possível fazer alterações nas hipóteses e teorias auxiliares quando uma previsão não se realiza. 
Kuhn (2001) divide o desenvolvimento científico em dois grandes componentes: ciência normal e revolução científica. No momento em que um novo grupo de cientistas começa a questionar o paradigma que domina determinado pensamento e os métodos de pesquisa dominantes num determinado campo do conhecimento, a ciência considerada ciência normal, apresentando a proposta de um novo paradigma capaz de direcionar os esforços de pesquisa para resolver problemas não reconhecidos ou não resolvidos pela comunidade partidária do paradigma até então vigente, tem-se a efetiva revolução científica.

O progresso de ciências, como a física, dentre outras, efetivamente se deu, na visão de Kuhn, através dessas revoluções, numa constelação de concepções, valores, percepções e práticas compartilhadas por uma comunidade, que dá forma a uma visão particular da realidade, a qual constitui a base da maneira como a comunidade se organiza, pensa e produz novo conhecimento. Segundo Kuhn (2001), devemos então compreender paradigmas como realizações científicas universalmente reconhecidas que, durante algum tempo, fornecem problemas e soluções modelares para uma comunidade de praticantes.

Kuhn (2001) não atribui o valor da ciência ao fato de ela seguir uma metodologia de verificação (positivismo lógico) ou de refutação e falseabilidade (racionalismo crítico), mas por ser conduzida sob a forma de paradigmas. Se uma teoria for capaz de solucionar a anomalia que gerou a crise, ela poderá se tornar um novo paradigma. No entanto, a disputa entre o paradigma predominante e o candidato a novo não pode ser decidida por critérios estritamente racionais uma vez que as revoluções científicas são episódios de desenvolvimento não-cumulativos e não-lineares de substituição de paradigma anteriores, agora incompatíveis com os novos. Não se podendo demonstrar a superioridade de um sobre o outro através da lógica ou da experiência, o critério mais adequado de aceitação cientifica fica sendo o consenso no sentido do seu reconhecimento por um grupo ou sociedade cientificamente representativo.

A contribuição da controvérsia entre Kuhn e Popper para o desenvolvimento da ciência discutida por Echeverry (2004) permite verificar que ambos os autores concordam que a ciência não progride de forma meramente cumulativa e que a analise do desenvolvimento do conhecimento cientifico precisa levar em consideração o modo como a ciência trabalha na realidade, bem como a necessidade critica de consenso e de coerência metodológica. Encontramos tanto em Popper quanto em Kuhn alguns pilares fundamentais para prática cientifica. Admitimos dessa forma, que tanto a perspectiva de Popper que considera o progresso científico como superação de teorias cientificas e o aparecimento de outras melhores e mais satisfatórias enquanto um matiz critico mais brando e gradual do conhecimento cientifico, como também a perspectiva de Kuhn de revolução a partir do surgimento de novos paradigmas que derrubam e anulam os anteriores enquanto matizes criticas 
mais fortes e radicais sejam perspectivas válidas tendo em vista a natureza dinâmica e interativa da produção cientifica e consequentemente da metodologia para o seu alcance.

No caso especifico da grande área de Engenharia de Produção, a falsa idéia de linearidade do conhecimento e o forte acento positivista e empirista que em certa medida predomina até o presente, levam a uma resistência às mudanças na forma de conceber o desenvolvimento cientifico. Muitas vezes encontram-se soluções “ótimas” baseadas em modelos matemáticos e simulações ausentes de clareza quanto ao problema, sua natureza, os objetivos da pesquisa ou a seleção de critérios sob os quais o problema será avaliado, ou seja, soluções para problemas que não se sabe exatamente quais são; soluções para problemas engessadamente dados em contextos mutantes ou ainda soluções descontextualizadas que pouco ou nada contribuem. (ENSSLIN et al, 2000).

Nesse sentido apontamos para necessidade de tomar o design da pesquisa como uma arquitetura de projeto capaz de propor cientificidade e uma metodologia adequada e coerente com problemas reais. A discussão que propomos em torno do design da pesquisa qualiquantitativa busca evidenciar a conveniência de antes de lançar-se na formulação (representação matemática de um contexto conhecido, isto é na modelagem) de problemas caracterizados por contextos sociais (situações onde pessoa(s) deve(m) avaliar e decidir) investir na compreensão do que esta(s) pessoa(s) julga(m) relevante neste contexto neste momento. (KEENEY, 1992). Reconhecendo que o que até o presente impediu estas pessoas de encontrar um caminho apropriado (solução, alternativa) é a falta de entendimento suficiente da situação. Reconhecendo igualmente que não há um modelo único para se construir conhecimentos confiáveis, e sim modelos mais ou menos adequados ao que se pretende investigar ou ao objetivo da pesquisa. E Reconhecendo igualmente que o problema do facilitador (modelador, cientista, consultor) é distinto do da(s) pessoa(s) que devem realizar a decisão. (ENSSLIN, 2000; ENSSLIN et al, 2001).

É preciso desenvolver processos próprios de investigação, expressos adequadamente no design da pesquisa, e avalia-los continuamente durante sua operacionalização, e assegurar-se que validem criticamente o progresso da mesma, verificando o rigor dos procedimentos e a confiabilidade das conclusões que não prescindem de evidências e argumentação sólida, tendo em vista atender os mais exigentes e sofisticados usuários da Pesquisa Operacional.

\section{Dois métodos: o caminho do objetivo de pesquisa}

A grande área da Engenharia de Produção esteve historicamente bastante voltada para o produto e os processos mecânicos a ele relacionados, vinculando o conhecimento cientifico, sobretudo em projetos de viabilidade de produtos, planejamento da produção, e distribuição de produtos ligando-se fortemente ao positivismo, ao empirismo e consequentemente ao quase 
monopólio dos métodos quantitativos ao longo do século XX.

Nesse sentido, em oposição à crescente insuficiência dos métodos quantitativos na Pesquisa Clássica, chamada Pesquisa Operacional Hard ou Hard-PO, e mais ainda em busca de superação do paradigma meramente positivista e empirista numa sociedade que se refez dos efeitos das duas grandes guerras e em processo crescente de globalização econômica, a partir da década de 60 a Pesquisa Operacional Soft, chamada Soft-PO vem considerando a complexidade social do problema e o envolvimento de múltiplos atores no saber cientifico e nas suas metodologias. (ENSSLIN, 1994).

O desafio de novos e emergentes papéis da Engenharia de Produção nas economias globalizadas aparece carregado de necessidades que não podem mais prescindir de incorporar a perspectiva da personalização dos contextos de trabalho e produção. Isto impõe limites à visão generalista dos problemas e passa a previlegiar a dimensão subjetiva (inerente ao sujeito, logo personalizada) no processo de delimitar e explicitar o que é importante (objetivos, critérios, atributos) e o que não é importante no problema. (ROY, 1994; ENSSLIN, 2000)

O design da pesquisa deve explicitar a forma de perscrutar o ambiente para captar a percepção do(s) decisor (es) e testar em forma contínua durante sua construção o alinhamento do que está sendo realizados com os valores, preferências e prognósticos do decisor. Particularmente então na discussão sobre a utilização do Método quali-quantitativo em Engenharia de Produção, ou na Soft-PO é preciso ressaltar a existência de uma relação dinâmica entre o mundo real e o sujeito-observador (decisor) que é, portanto, parte do processo de conhecimento que interpreta, compreende e atribui significado aos fenômenos, de acordo com seus valores e crenças. Evidenciase dessa forma uma fundamentada justificativa cientifica para o uso da abordagem qualiquantitativa , tendo em vista as inúmeras críticas acerca de sua validade e condições de aplicação e mesmo a errônea suposição de que esse tipo de saber possa ser arbitrário.

A validade da pesquisa seja ela quantitativa qualitativa ou quali-quantitativa depende de um rigor científico disciplinado por uma rigorosa obediência aos fundamentos científicos, a sociedades científicas, mas também ao atendimento das necessidades de seus usuários (usabilidade). A ausência de um dos três elementos compromete sua validade. (ROY, 1993). A abordagem quali-quantitativa não é oposta ou contraditória em relação à pesquisa quantitativa, ou a pesquisa qualitativa, mas de necessária predominância ao se considerar a relação dinâmica entre o mundo real, os sujeitos e a pesquisa, ainda mais quando se intensificam os consensos nos questionamentos acerca das limitações da Pesquisa Operacional Clássica em incorporar os sujeitos, objetos e ambientes no contexto de construção do conhecimento e consequentemente nas metodologias de pesquisa. 
É fundamental assumir inicialmente que resolver um problema na área da Engenharia da Produção, é um processo, com alguns dados novos sendo incorporados e outros desprezados ao longo do tempo, e que novas questões podem aparecer e substituir as originalmente propostas e os fenômenos podem e são cada vez mais caracterizados por um alto grau de complexidade interna e de dinamicidade.

Para Merrian (1998), independente do tipo de pesquisa adotado, a base filosófica está normalmente fundamentada na visão de que a realidade é construída por indivíduos que interagem com seu mundo social.

O processo de validação e as condições de aplicação da pesquisa de predominância qualiquantitativa apontam para necessidade de construção de um consistente design de pesquisa que favoreça a avaliação por robustos critérios de cientificidade e aderência ao problema como percebido por seu interlocutor (decisor). A primeira denominada validação e a segunda legitimação do design de pesquisa. (ROY, 1993; MISER, 1993; ORAL E KETANY, 1993; LAUNDRY, 1995).

\section{O papel do Design no rigor da Pesquisa Operacional Soft em Engenharia de Produção}

Para Yin (2001) um projeto de pesquisa é um plano de ação para se sair daqui e chegar lá, onde aqui pode ser definido como o conjunto inicial de questões a serem respondidas e lá é um conjunto de conclusões e respostas sobre essas questões. Embora essa conceituação seja um tanto estática, nos dá a idéia geral do design de pesquisa.

Já Mason (1996) identifica que um projeto de pesquisa é composto dos motivos da pesquisa, do escopo da mesma, além de desenvolver o conhecimento do próprio pesquisador. Os pontoschave do projeto de pesquisa são a clareza sobre a essência do questionamento, que deve estar amparado em um quebra-cabeça intelectual formulado; a interligação das questões da pesquisa com as metodologias e métodos; a verificação dos conceitos éticos e a praticabilidade de construir o projeto em consonância com o que foi apresentado. O autor não propõe exatamente uma estrutura de projeto de pesquisa, mas questionamentos acerca dos pontos-chave. Essa proposta é relevante por propor uma vigilância continua acerca da essência do problema.

Merrian (1998) considera que a primeira tarefa na condução de um estudo de pesquisa é o objetivo da resolução do problema. A estrutura teórica é o esqueleto da pesquisa. Nessa estrutura são apresentados os questionamentos da pesquisa, a identificação do que é relevante, o projeto de como representá-lo e mensurá-lo a forma como será feito o levantamento de dados, que métodos serão utilizados para analisar os dados coletados e de que forma os dados serão interpretados.

Cabe destacar que o processo para projetar um estudo não acontece linearmente no tempo. Existe uma interação nesse processo que é cíclico. Dessa forma entendemos que o design de 
pesquisa quali-quantitativa seja um constructo teórico e prático dinâmico, um mapa de navegação com uma estrutura orientadora de um processo continuamente aberto ao questionamento acerca dos pontos-chave do problema levantado e possível de ser avaliado sob critérios de validade cientifica. Nossa proposta teórica é que esse plano ou design de pesquisa particularmente em Engenharia de Produção seja robustecido pela constante avaliação sob os critérios de validade cientifica de DEMO (1986), o que favorece a vigilância disciplinada dos objetivos e da essência da pesquisa, alem da coerência interna com o método predominante, seja quais forem os paradigmas nos quais se esteja operando, melhorando ou mesmo superando.

Admitindo também que a ciência seja um produto social, histórico e em processo de formação. Demo (1986), propõe quatro critérios internos e um critério externo de cientificidade. Os critérios internos são a coerência, a consistência, a originalidade e a objetivação.

A coerência significa a argumentação lógica, concatenada, premissas iniciais, construção do discurso e de conclusões congruentes entre si. A consistência traduz-se na capacidade de resistir ao contraditório; refere-se à qualidade argumentativa do discurso. A originalidade diz respeito a uma produção inovadora, que permite ao conhecimento avançar. A objetivação é a palavra empregada pelo autor para substituir o conceito de objetividade, e tem por significado a tentativa de reproduzir a realidade o mais próximo possível do que é, ou seja, expressa a busca de uma aproximação cada vez maior entre sujeito-objeto-ambiente em que o conhecimento ocorre, é construído e utilizado.

DEMO (1986) aponta como critério externo de cientificidade, a intersubjetividade, significando a ingerência da opinião dominante dos cientistas de determinada época e lugar de demarcação científica, em outras palavras, a vigência do argumento de autoridade em ciência.

Quadro 1: Critérios de Cientificidade de DEMO

\begin{tabular}{|c|c|c|c|c|}
\hline \multicolumn{4}{|c|}{ CRITÉRIOS INTERNOS } & CRITÉRIO EXTERNO \\
\hline Coerência & Consistência & Originalidade & Objetivação & intersubjetividade \\
\hline $\begin{array}{c}\text { Discurso } \\
\text { logicamente } \\
\text { construído }\end{array}$ & $\begin{array}{l}\text { Qualidade } \\
\text { argumentativa } \\
\text { do discurso; }\end{array}$ & $\begin{array}{l}\text { Contribuição do } \\
\text { conhecimento }\end{array}$ & $\begin{array}{c}\text { Abordagem } \\
\text { teórico- } \\
\text { metodológica de } \\
\text { aproximação da } \\
\text { realidade }\end{array}$ & $\begin{array}{c}\text { A ingerência da opinião dominante dos } \\
\text { cientistas de determinada época e lugar de } \\
\text { demarcação científica }\end{array}$ \\
\hline
\end{tabular}

Fonte: Baseado nos critérios de DEMO (1986)

Dessa forma, propomos uma arquitetura do projeto de pesquisa ou um design de pesquisa quali-quantitativa em engenharia de produção que se pretende alinhado com o referenciado teoricamente. 
Figura 2 - O Design da Pesquisa Qualitativa e os critérios de validadE

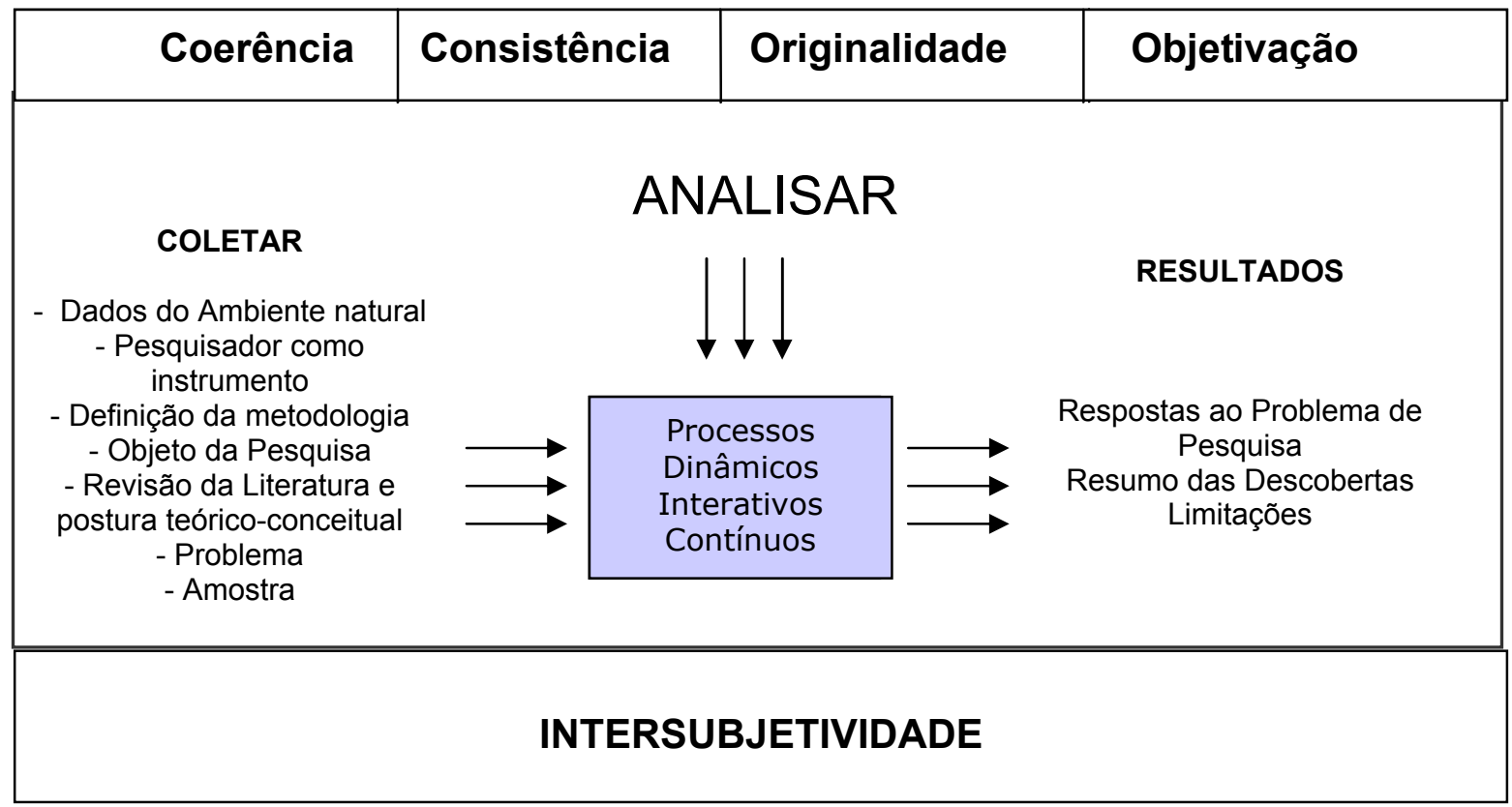

Fonte: os autores baseado nos critérios de DEMO(1986)

Triviños (1992) chama de "indisciplina intelectual", uma incoerência entre os suportes teóricos e a prática social. Decorre desse conceito que, quando não está consciente dos fundamentos da tradição de pesquisa no qual seu estudo está inserido, o pesquisador tende a misturar autores, citações, metodologias de correntes de pensamento contraditórias. As razões para a falta de disciplina apresentadas por Triviños (1992) são de natureza múltipla: têm origem histórica e se manifestam de diversos modos. Primeiro porque a formação profissional é unilateral e muitas vezes preconceituosa, sonegada de uma ampla faixa de idéias, tornando nosso espírito crítico limitado e acostumando-se a não aceitar as idéias de inovação, bem como pela dependência cultural e econômica que favorece a acomodação, o conservadorismo, o apoio ao estabelecido e a falta de criatividade.

Dessa forma, ao propormos a utilização prática do design de pesquisa quali-quantitativa em engenharia de produção, justificamos ao recorrer ao conceito de indisciplina de Triviños (1992) que pode ser entendida como a ausência de coerência entre os suportes teóricos e a prática social, que deve ser evitada. O principal papel que o design deve desempenhar é justamente o de favorecer a disciplina e a coerência na pesquisa.

\section{O uso disciplinado dos métodos quali-quantitativos em Engenharia de Produção}

Ao analisarmos quando utilizar o método quali-quantitativo na Soft-PO identificamos que há certo acordo quanto à sua utilidade em estudos exploratórios, aqueles em que se tem pouco conhecimento inicial sobre o problema investigado e suas fronteiras. Porém, é a natureza do 
problema que deve indicar de forma mais clara a utilização da pesquisa quali-quantitativa. Essa abordagem é indicada para a compreensão de fenômenos caracterizados por um alto grau de complexidade interna num ambiente de incerteza. O universo não passível de ser captado por hipóteses perceptíveis, verificáveis e de difícil quantificação inicial é também um campo interessante para utilização dessa abordagem.

Os autores consideram que a pesquisa de predominância quali-quantitativa em engenharia de produção de uma maneira geral pode ser utilizada para explorar melhor as questões pouco estruturadas, os territórios ainda não mapeados, os horizontes inexplorados, problemas que envolvem atores, contextos e processos. Destaque-se que os problemas em Engenharia de Produção são em sua origem qualitativos. À medida que seu grau de entendimento cresce sua forma de compreensão evolue e alcança seu máximo grau de acuracidade qualitativa com a representação do grau de desempenho de suas dimensões via escalas ordinais. Para este grau de entendimento crescer ele necessita ter uma representação mais acurada e isto só é possível com a incorporação de novas informações cardinais transformando as informações qualitativas em quantitativas. Os modelos quali-quantitativos são, portanto, uma evolução dos modelos meramente qualitativos ou quantitativos.

Os estudos de processo, particularmente quando combinados a estudos longitudinais, apontam como melhor escolha metodológica a pesquisa quali-quantitativa, sobretudo porque os processos estudados na área de engenharia de produção caracterizam-se pela existência de grande número de fatores para os quais o uso ainda não consolidou uma escala para aferir seu desempenho, por um lado e, por outro, pelo fato de as escalas mesmo aquelas representadas por números usualmente não serem cardinais, mas ainda serem simples escalas ordinais. O design da pesquisa deve explicitar os tipos de escalas a serem utilizadas em cada uma de suas etapas e a forma de sua transformação em escalas cardinais, se for este o caso.

Nesse sentido, a estrutura de design proposto pode ser útil, pois serve com vantagens à análise da realidade cada vez mais complexa do desenvolvimento global, com seus novos cenários e o desafio de levar em consideração cada vez mais o olhar das pessoas envolvidas nos processos de produção de bens, serviços e conhecimento, para conferir-lhes legitimidade, e usabilidade, por um lado e os fundamentos científicos que lhe conferem validade e fundamentação por outro.

No entanto, há um aspecto que pode ser particularmente problemático na utilização da pesquisa quali-quantitativa em engenharia de produção: a multiplicidade ou mistura aleatória de procedimentos associados a diferentes posturas teóricas e epistemológicas sem a devida coerência num campo onde o investigador é o instrumento primário, na coleta e análise de dados e, também responde pela melhoria nas oportunidades para a coleta e produção de informações significativas, sendo que para Triviños (1992) as características pessoais do pesquisador devem ser a tolerância à 
ambigüidade; a sensibilidade (muita intuição); boa comunicação e a capacidade de escutar.

Nesse sentido, o atual estágio dos currículos de formação em Engenharia de Produção no Brasil, sugere a necessidade de uma formação especifica particularmente ligada aos pressupostos epistemológicos da pesquisa quali-quantitativa, que seja capaz de garantir minimamente o seu uso disciplinado uma vez que os métodos quali-quantitativa exigem um grande investimento de tempo e pessoal qualificado para esse trabalho e as habilidades e competências interpessoais do pesquisador sejam fundamentais nesse processo de apreensão das realidades. Particularmente a habilidade interativa do pesquisador reflete-se na qualidade dos dados que obtém. Essa tarefa, embora possa parecer simples, demanda treinamento em profundidade e, sobretudo mudança de mentalidade.

\section{Considerações Finais}

O desenvolvimento científico em Engenharia de Produção necessita cada vez mais caracterizar-se criticamente por uma multiplicidade de abordagens, com pressupostos, metodologias, estilos e paradigmas diversos que possam atender suas peculiares características sistêmicas e holísticas e atender as demandas das economias cada vez mais globalizadas sem descurar as clássicas tarefas de produção.

É nesse sentido que empreender novos caminhos metodológicos em Engenharia de Produção, ou mais do que isso, incorporar a predominância de métodos quali-quantitativos na pesquisa implica em certa medida em abandonar a segurança e o alto grau de certeza da predominância ou dominância dos modelos quantitativos matemáticos em primeira mão e uma dedicada tarefa critica de utilização do design de pesquisa para orientar ou não, quando e como fazer uso desses instrumentos ao longo do processo.

A principal questão reside dessa forma, não no método, mas na articulação válida entre método e teoria, entre técnica, fundamento conceitual e prática social. Em vista desse disciplinado senso de autocrítica que garanta a cientificidade e a validade da pesquisa quali-quantitativa é que propusemos uma arquitetura do design de pesquisa que não apenas incorpore os principais elementos materiais do processo, como também atenda a critérios formais sob os quais se possa avaliar de forma dinâmica a própria pesquisa ao longo de seu desenvolvimento tanto no que se refere aos elementos materiais (dados, amostras, descobertas...), mas, sobretudo nos seus elementos formais ou nos critérios de sua validade interna (coerência, consistência, originalidade, objetivação) e externa (intersubjetividade) e na sua finalidade prática.

Tendo no investigador o principal agente do desenvolvimento cientifico, encontramos na necessidade de sua formação especifica e profunda para pesquisa quali-quantitativa - uma dimensão estratégica para o desenvolvimento crítico e válido na área de engenharia de produção. 


\begin{abstract}
The present paper intends to present a proposition of design for qualitative research applied to production engineering which contemplates material and formal elements in the investigative process, concentrating the discussion on the epistemological basis of the scientific development in the internal and external criteria of validity of the qualitative research and in the formation of the researcher as a primary and strategic element of the production process of critical and valid knowledge in this area of knowledge. Firstly the controversy between Popper and Kuhn in relation to the scientism and scientific method is presented and then later presenting the construct of the authors about this. Then the qualitative and quantitative methods are characterized, justifying the need of the predominance of the qualitative approach in some areas of production engineering. The third section is about the research project, its characteristics, its formal and material elements, and the use of internal and external validation criteria in a disciplined way, the use of the qualitative research and the formation of the researcher.
\end{abstract}

Key-words: Operational Research; Quali-quantitative Research; multicritery.

\title{
5. Referências
}

DEMO, P. Metodologia científica em ciências sociais. São Paulo: Atlas, 1986.

ECHEVERRI, Luis Guilhermo J.;GARCIA, Juan Carlos A. La Controversia Kuhn - Popper en torno al Progreso Científico $y$ sus posibles aportes a la Enseñanza de las Ciencias. Disponible: http://www.moebio.uchile.cl/20/jaramillo.htm Cinta de Moebio, Septiembre, numero 20, Universidad de Chile, Santiago-Chile, 2004.

ENSSLIN, L. Avaliação e Perspectivas da Engenharia Econômica. In: XIV ENEGEP - ENCONTRO NACIONAL DE ENGENHARIA DE PRODUÇÃO, 1994, João Pessoa - Paraíba: 1994. v. 1, p. IX - XX.

ENSSLIN, L.; DUTRA, A.; ENSSLIN, S. MCDA: a constructivist approach to the management of human resources at a governmental agency. International Transactions in Operational Research, n. 7, p. 79-100, 2000.

cross ${ }^{\text {ref }}$

ENSSlin, L.; MONTIBElleR, G.; NORONHA, S. Apoio à Decisão - Metodologia para Estruturação de Problemas e Avaliação Multicritério de Alternativas. Florianópolis, Insular, 2001.

ENSSLIN, S. A incorporação da Perspectiva Sistêmico-Sinergética na Metodologia MCDA - construtivista: uma ilustração de implementação. Tese - Doutorado em Engenharia de Produção. Programa de Pós-graduação em Engenharia de Produção. Universidade Federal de Santa Catarina. Florianópolis, 2002.

KEENEY, R.L. Value-Focused Thinking: A Path to Creative Decisionmaking, Harvard University Press, 1992.

KUHN, T. S. (1962) La estructura de las revoluciones científicas. México: Fondo de Cultura Económica, 2001.

LANDRY, M. Note on the concept of problem: A Piagetian perspective, Working Paper, Faculté des Sciences de l'Administration, Université Laval, Québec, 1995.

MASON, J., Qualitative Researching, SAGE Publications, London / Thousand Oaks, Calif. Rice P and Ezzi D, 1999.

MERRIAN, S. B., Qualitative Research and Case Study Applications in Education, San Francisco: Jossey-Bass Publishers, 1988.

MISER, H.J., A foundational concept for validation in operational research. European Journal of Operational Research, v. 66, p. $204-215,1993$.

cross ${ }^{\text {ref }}$ 
ORAL, M., KETTANI,O. The facets of the modelling and validation process in operatios research. European Journal of Operational Research, v. 66, p. 216-234, 1993.

\section{cross ${ }^{\text {ref }}$}

PETRI, Sérgio Murilo. Modelo para apoiar a avaliação das abordagens de gestão de desempenho e sugerir aperfeiçoamentos: sob a ótica construtivista. 2005. 235 f. Tese de Doutorado (Doutorado em Engenharia de Produção). Programa de Pós-Graduação em Engenharia de Produção. Universidade Federal de Santa Catarina, Florianópolis, 2005.

POPPER, K. (1959). A lógica da pesquisa científica. São Paulo, Editora Cultrix, 1998.

ROY, B. Decision science or decision-aid science?. European Journal of Operacional Research, v.66, pp. 184-203, 1993.

cross'ef

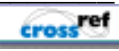

On Operational Research and Decision Aid ; EJOR 73 ( 1994) 23-26.

TRIVINOS, Augusto Nibaldo Silva. Introdução à Pesquisa em Ciências Sociais: a pesquisa qualitativa em educação. São Paulo: Atlas, 1992.

YIN, R. K. Estudo de caso: planejamento e métodos. 2a edição. Porto Alegre: Bookman, 2001.

\section{Dados completos dos autores}

Leonardo Ensslin

Universidade Federal de Santa Catarina

Departamento de Engenharia de Produçào e e Sistemas

Professor Titular

Departamento EPS - CTC-UFSC

Trindade Cx Postal 476

CEP 88.010-970 Florianópolis SC

Telefones para contato: ( 48 ) 3721 - 7022

e-mail:ensslin@deps.ufsc.br

Sandra Rolim Ensslin

Universidade Federal de Santa Catarina

Departamento de Ciências Contábeis

Professora Adjunta

Departamento CCS - CSE-UFSC

Trindade Cx Postal 476

CEP 88.010-970 Florianópolis SC

Telefones para contato: (48) 3721- 6635

e-mail:ensslin@deps.ufsc.br 
William Barbosa Vianna

Doutorando da Universidade Federal de Santa Catarina (UFSC)

Departamento de Engenharia de Produçao e Sistemas

Rua Cônego Bernardo, 100. Ap. 202 - Trindade - Florianópolis - SC - 88036-570

Telefones para contato: 48.8421 .0241

e-mail: wpwilliam@hotmail.com

Recebido para publicação em: 17/07/07

Aceito para publicação em: 30/05/07 